\title{
KUALITAS AIR PADA KOLAM LOBSTER AIR TAWAR (Cherax quadricarinatus) DI BBAT TATELU
}

\author{
Sipriana S. Tumembouw ${ }^{1}$
}

\begin{abstract}
The study was done at the culture site and in the laboratory. The former covered water temperature and $\mathrm{pH}$ in the spawning, nursery and rearing ponds, in the morning, 06:00-07:00, at noon,12:00-13.00, and in the afternoon 17:00 to 18:00. Measurements were taken for 2 weeks. The latter included Dissolved Oxygen (DO), Ammonia, Nitrite, Carbon Dioxide (CO2) and turbidity. Water samples were analyzed in the Laboratory of Freshwater Aquaculture Center (BBAT) Tatelu, North Minahasa. Results showed that water temperature, $\mathrm{pH}, \mathrm{DO}, \mathrm{CO} 2$, turbidity, ammonia and nitrite were in the suitable range for the freshwater lobster culture, except that DO, CO2, turbidity, ammonia in the spawning and rearing ponds on March 14, 2011 were either lower or higher than the National Water Quality Standard for aquaculture.
\end{abstract}

Keywords: Water Quality Parameter, Laboratory, Pond, Water Quality Standard.

\begin{abstract}
ABSTRAK
Penelitian dilakukan di tempat budidaya lobster dan di laboratorium. Pengukuran lapangan meliputi suhu air dan $\mathrm{pH}$ di kolam pemijahan, pendederan, dan pembesaran, pada pagi hari (06:00-07:00), siang hari (12:00-13.00), dan sore hari (17:00-18:00). Pengukuran dilakukan selama dua minggu. Pengukuran laboratorium meliputi Oksigen terlarut (DO), Amonia, Nitrit, Karbondioksida $\left(\mathrm{CO}_{2}\right)$ and kekeruhan. Sampel air dianalisa di laboratorium Balai Budidaya Air Tawar, (BBAT) Tatelu, Minahasa Utara. Hasil menunjukkan bahwa suhu air, $\mathrm{pH}, \mathrm{DO}, \mathrm{CO}_{2}$, kekeruhan, amonia dan nitrit berada dalam kisaran yang sesuai untuk budidaya lobster air tawar, kecuali bahwa $\mathrm{DO}, \mathrm{CO}_{2}$, kekeruhan, amonia di kolam pemijahan dan pembesaran pada 14 Maret 2011 berada lebih rendah maupun lebih tinggi daripada standar bakumutu air nasional untuk budidaya.
\end{abstract}

Kata kunci: Parameter kualitas air, laboratorium, air kolam, bakumutu.

${ }^{1}$ Staf pengajar Fakultas Perikanan dan Ilmu Kelautan Universitas Sam Ratulangi, Manado, Sulawesi Utara

\section{PENDAHULUAN}

Cherax quadricarinatus atau lobster air tawar dikenal dengan nama red claw, termasuk dalam anggota Famili Parastacidae merupakan jenis lobster yang habitatnya berasal dari Queensland, Australia. Ciri utama lobster ini adalah di kedua ujung capitnya berwarna merah. Lobster air tawar dikenal di Indonesia pada tahun 1990 sebagian ikan hias, memasuki tahun 2000, bisnis lobster air tawar mulai popular karena telah ditemukan teknik budidaya yaitu pembenihan dan pembesaran lobster air tawar di berbagai lokasi atau wilayah (Kurniawan dan Hartono 2007). Pada tahun 2002-2003, usaha budidaya lobster air tawar mulai me- ningkat, yang awalnya diminati sebagai ikan hias berubah menjadi komoditas konsumsi (Sukmajaya dan Suharjo 2003).

Berkembangnya usaha budidaya lobster air tawar karena tingginya permintaan pasar baik dalam keadaan hidup maupun beku. Lobster air tawar memiliki beberapa keunggulan yaitu lebih mudah dibudidayakan, memiliki pertumbuhan yang relatif cepat, relatif tahan terhadap penyakit, memiliki kandungan gizi yang sangat tinggi, kadar lemak rendah serta struktur daging yang relatif gurih dan empuk. Disamping itu juga memiliki nilai jual yang relatif tinggi (Lukito dan Prayugo, 2007).

Sumber air merupakan pertimbangan yang sangat penting dalam pemelihara- 
an lobster air tawar karena untuk memelihara lobster air tawar memerlukan air yang cukup, serta air yang digunakan harus berkualitas baik sehingga pertumbuhan lobster menjadi lebih cepat. Penilaian terhadap kualitas air yang baik meliputi temperatur, derajat keasaman $(\mathrm{pH})$, kandungan amoniak dan kekeruhan (Alaerts dan Santika 1987). Beberapa persyaratan kualitas air untuk budidaya lobster air tawar yang ideal yaitu temperatur dalam pemeliharaan lobster air tawar adalah $24-31^{\circ} \mathrm{C}$. Derajat keasaman $(\mathrm{pH})$ yang pada kisaran $6-8$, kandungan amoniak dalam air maksimal 1,2 ppm, tingkat kekeruhan pada angka 30-40 $\mathrm{cm}$ (Setiawan, 2006). Penelitian ini mengukur dan menganalisis parameter kualitas air lobster air tawar yang meliputi suhu, $\mathrm{pH}$, oksigen terlarut (DO), amoniak, nitrit, karbondioksida $\left(\mathrm{CO}_{2}\right)$ dan kekeruhan pada kolam pemijahan, pendederan dan pembesaran (Setiawan, 2006).

\section{METODE PENELITIAN}

Adapun metode yang digunakan:

Tabel 1. Parameter yang diambil dalam

\begin{tabular}{lllll}
\multicolumn{5}{c}{ penelitian ini. } \\
\hline No & \multicolumn{1}{c}{ Parameter } & \multicolumn{1}{c}{ Satuan } & \multicolumn{1}{c}{$\begin{array}{l}\text { Metode } \\
\text { Analisis }\end{array}$} & \multicolumn{1}{c}{ Alat } \\
\hline 1 & Temperatur & ${ }^{\circ} \mathrm{C}$ & Pemuaian & Termometer \\
2 & Kekeruhan & meter & Turbidity & Turbiditymeter \\
3 & pH & derajat keasaman & Potensiometer & pH meter \\
4 & $\mathrm{DO}$ & $\mathrm{mg} / \mathrm{l}$ & DO meter & DO meter \\
5 & $\mathrm{Ammoniak}\left(\mathrm{NH}_{3}+4\right)$ & $\mathrm{mg} / \mathrm{l}$ & Nesslerisasi & Spectrophotometer \\
6 & Nitrit $\left(\mathrm{NO}_{2}\right)$ & $\mathrm{mg} / \mathrm{l}$ & Diazozation & Spectrophotometer \\
7 & Karbondioksida $\left(\mathrm{CO}_{2}\right)$ & $\mathrm{mg} / \mathrm{l}$ & Titrasi & Grafik \\
\hline
\end{tabular}

Data yang diperoleh selama penelitian dianalisis secara deskriptif dan ditampilkan dalam bentuk tabel, grafik dan histogram kemudian dibandingkan dengan PP RI. No. 82 Tahun 2001 Tentang Pengelolaan Kualitas Air dan Pengendalian Pencemaran Air.

\section{HASIL DAN PEMBAHASAN}

Data hasil pengukuran parameter suhu pada satu titik di kolam budiaya lobster air tawar dapat dilihat pada Gambar 1 dan 2 . Untuk data hasil pengukuran parameter $\mathrm{pH}$ pada satu titik di kolam budiaya lobster air tawar dilihat pada Gambar 3 dan 4. Sedangkan data hasil pengukuran parameter DO pada satu titik di kolam budiaya lobster air tawar dilihat pada Gambar 5 dan 6.

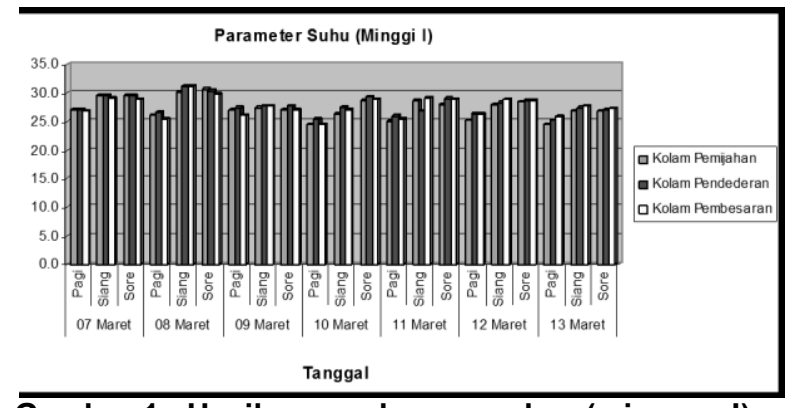

Gambar 1. Hasil pengukuran suhu (minggu I) di kolam budidaya lobster air tawar.

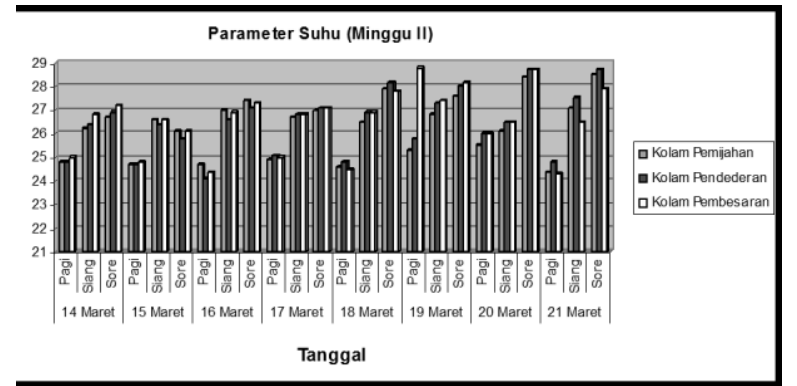

Gambar 2. Hasil pengukuran suhu (minggu II) di kolam budidaya lobster air tawar.

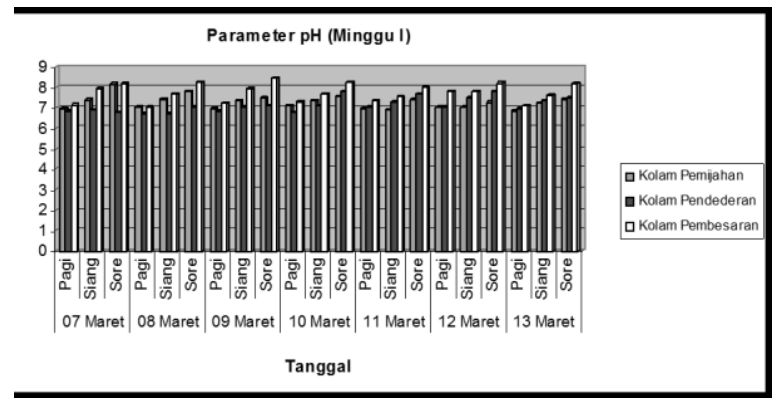

Gambar 3. Hasil pengukuran $\mathrm{pH}$ (minggu I) di kolam budidaya lobster air tawar.

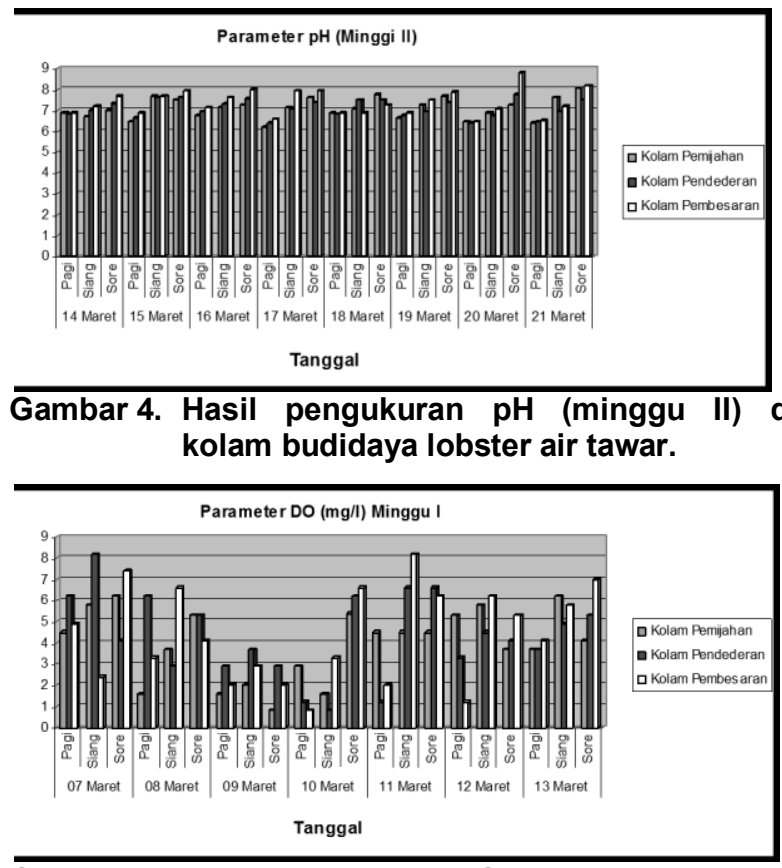

Gambar 5. Hasil pengukuran DO (minggu I) di kolam budidaya lobster air tawar. 


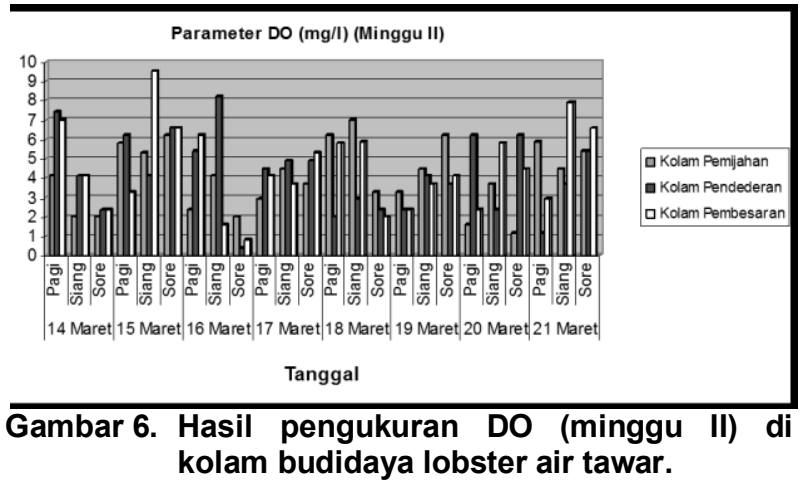

Data hasil parameter kualitas air di kolam Budidaya Lobster Air Tawar (BBAT) Tatelu (7 Maret 2011).

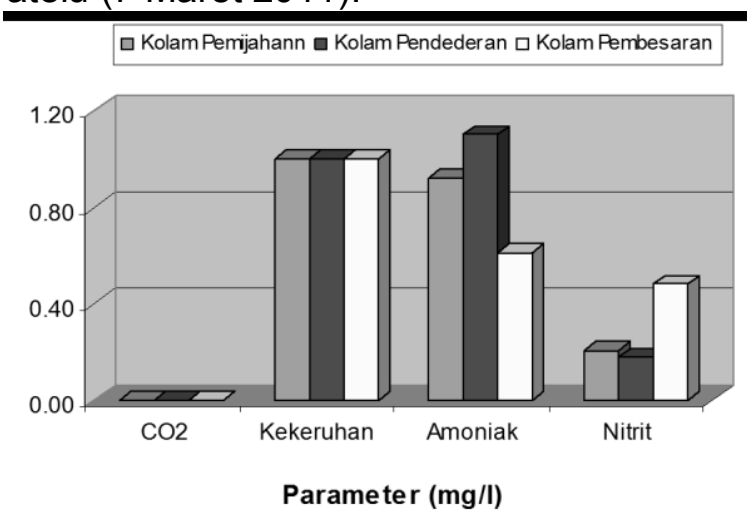

Gambar 7. Hasil pengukuran kualitas air di kolam budidaya lobster air tawar (BBAT) Tetelu (7 Maret 2011).

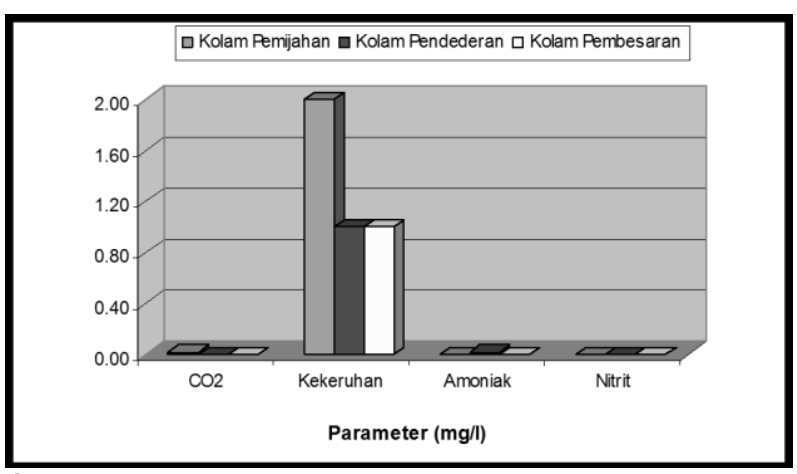

Gambar 7. Hasil pengukuran kualitas air di kolam budidaya lobster air tawar (BBAT) Tetelu (14 Maret 2011).

Rata-rata pengukuran suhu terendah berada di kolam pemijahan dan dibandingkan dengan baku mutu masih berada ambang batas, hal ini disebabkan pada saat pengukuran cuaca hujan. Perubahan suhu air yang terlalu ekstrem membuat lobster sulit beradaptasi, hal ini menyebabkan pertumbuhan lobster terhambat. Rata-rata $\mathrm{pH}$ terendah berada pada kolam pemijahan karena pada saat itu keadaan cuaca hujan maka mempengaruhi $\mathrm{pH}$ yang diperoleh. DO rata-rata terendah berada di kolam pendederan dan DO tertinggi berada pa- da kolam pembesaran, hal ini disebabkan keadaan cuaca hujan.

Hasil analisis karbondioksida, kekeruhan di kolam pemijahan, pendederan dan pembesaran masih berada pada kondisi normal, sedangkan hasil analisis kandungan ammonia, nitrit melewati ambang batas, hal ini disebabkan oleh hasil buangan kotoran lobster dan sisa pakan yang jika dibiarkan dalam waktu lama akan terakumulasi dan menjadi racun bagi lobster. Kadar amoniak dalam air perlu dipantau, yakni maksimum $1 \mathrm{ppm}$. Adanya amoniak dalam air akan mempengaruhi pertumbuhan biota budidaya (Bachtiar 2006). Nitrit merupakan bentuk peralihan antara amoniak dan nitrit (nitrifikasi) dan antara nitrat dan gas nitrogen (denitrifikasi).

Hasil analisis karbondioksida, kekeruhan, ammonia, nitrit di kolam pemijahan, pendederan dan pembesaran masih berada pada kondisi normal. Hal ini disebabkan keberadaan media air tempat pemeliharaan lobster mengalir menyebabkan kondisi air saat dilakukan pengukuran hasilnya masih berada dalam kondisi normal.

\section{KESIMPULAN}

Berdasarkan pengujian parameter kualitas air lobster air tawar (BBAT) Tatelu di Kecamatan Dimembe yaitu pada lokasi kolam budidaya yang meliputi pengukuran suhu, $\mathrm{pH}$, oksigen terlarut (DO), Karbondioksida $\left(\mathrm{CO}_{2}\right)$, kekeruhan, amoniak, nitrit, dapat disimpulkan bahwa suhu, $\mathrm{pH}$ dan amoniak pada kolam pendederan adalah alami. Namun untuk oksigen terlarut (DO), karbondioksida $\left(\mathrm{CO}_{2}\right)$, kekeruhan, amoniak di kolam pemijahan dan pembesaran tanggal 14 maret 2011 dan kolam pemijahan, pembesaran masih perlu peninjauan lanjut, melihat kondisinya yang di bawah dan melewati batas bakumutu air menurut PP No. 82 Tahun 2001 dan referensi lengkap budidaya.

\section{DAFTAR PUSTAKA}

Alaerts, G. Dan S.S. Santika., 1987. Metode Penelitian Air. Usaha Nasional. Surabaya.

Bachtiar, Y. 2006. Usaha Budidaya Lobster Air Tawar di Rumah. Agromedia Pustaka, Jakarta. 
Boyd, C.E. and F. Lichkopper. 1979. Water Quality Managemen in Pont Fish culture. Aubum University Agricultural Experimental Station. Alabama.

Cobb. J.S. and F.P. Bruce. 1980. The Biology and Management of Lobster Academic Press London. New York.

Kurniawan, T. Dan Hartono, 2007. Pembesaran Lobster Air Tawar Secara Cepat. Penebaran Swadaya, Jakarta
Lukito, A dan Prayugo, S. 2007. Panduan Lengkap Lobster Air Tawar. Penebar Swadaya. Jakarta. 292 Hal.

Sukmajaya, Y dan I. Suharjo. 2003. Lobster Air Tawar. Agromedia Pustaka.

Setiawan, C. 2006. Teknik Pembenihan dan Cara Cepat Pembesaran Lobster Air Tawar. Agromedia Pustaka, Jakarta. 